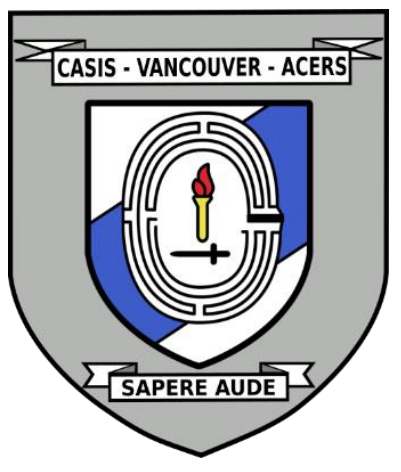

\title{
RADICALIZATION AND VIOLENT EXTREMISM IN THE ERA OF COVID-19
}

Date: January $21^{\text {st }}, 2021$

Disclaimer: This briefing note contains the encapsulation of views presented by the speaker and does not exclusively represent the views of the Canadian Association for Security and Intelligence Studies.

\section{KEY EVENTS}

On January 21, 2021, the Canadian Association for Security and Intelligence Studies (CASIS) Vancouver hosted its first digital roundtable event of the year, Radicalization and Violent Extremism in the Era of COVID-19. The presentation was conducted by guest speaker, Dr. Garth Davies, an Associate Professor in the School of Criminology at Simon Fraser University. He is also currently involved in developing data for evaluating programs for countering violent extremism. Dr. Davies' presentation provided an overview of the changes that society has had to make in adapting to the COVID-19 pandemic and shared some of his research findings on radicalization and violent extremism online during the pandemic. The increase in working remotely and being on the Internet has possibly contributed to a larger dissemination of misinformation leading people to certain extremist sites and forums that may contribute to radicalization. Additionally, Dr. Davies answered questions submitted by the audience, which focused on online radicalization, online platforms used for recruiting by extremist groups, misinformation, and the Incel movement.

\section{NATURE OF DISCUSSION}

\section{Presentation}

The internet has increasingly become a more prevalent tool used for all activities, including violent extremism and radicalization. The use of online platforms as radicalization tools is not necessarily a new tactic; however, they have possibly been used a lot more during the COVID-19 era. Technological advancements have potentially increased online activity during the pandemic. Yet, the increased use of the Internet does not immediately imply that online radicalization is occurring at a higher rate. Dr. Davies presented his research findings as to the types of internet radicalization that may be currently occurring. As internet use becomes more prevalent, it is important to study the potential security threats that may increase, such as violent extremism and radicalization. Especially, regarding 
the West Coast landscape and threats of right-wing extremism (RWE) that are increasingly present. Thus, Dr. Davies shared his findings and the possible current outlook of violent extremism and radicalization in the era of COVID-19.

\section{Question Period}

During the question and answer period, the prevalence of radicalization was discussed, particularly with regard to RWE and online radicalization. The possible reasons for an increase in online radicalization among RWE were also mentioned. The COVID-19 pandemic has potentially played a role in this prevalence, but its exact role has not been determined. The potential relationship between COVID-19 conspiracy theories and RWE was also discussed. Additionally, the rise in the Incel movement and their online presence was examined.

\section{BACKGROUND}

\section{Presentation}

Pandemics are not new to humankind. In comparison to the COVID-19 pandemic response, responses to past pandemics have differed, but also share similarities. The spread of misinformation and stigmatization have been found to be common during pandemics throughout different eras. It is important to take note of the political and societal responses that occur during pandemics. During the COVID19 pandemic, social injustices have been a prevailing narrative.

The COVID-19 pandemic has forced activities to move online and has prompted the use of online platforms such as Zoom to host business meetings, work assignments, and school classes. With the increase in online activities, technology is also expanding and introducing individuals to new means and platforms of communication. The ease in online communication offers the opportunity for information to be spread to whomever at a fast rate. Therefore, misinformation, scapegoating, and stigmatization have possibly been disseminated much more than before. The consequences of disinformation and conspiracies have the likelihood of feeding and influencing people in a way in which they may become radicalized. Dr. Davies studied this radicalization by examining online posts and behavior before and after the World Health Organization (WHO) declared COVID-19 a pandemic on March 11, 2020.

Dr. Davies' study consisted of examining seven online extremist forums: Stormfront, Free Republic, Incels.co, Lookism, Gawaher, TurnTolslam, and LibCom. Two RWE, two Incel, two Jihadist, and one left-wing extremism forum were analyzed. The data was mined and downloaded with the use of the 
Terrorism and Extremism Network Extractor tool. An analysis of Stormfront between January and March 2020 revealed no variation in violent extremism and radicalization posts. However, some of the findings from the study once the WHO declared COVID-19 a pandemic included an increase in posts on RWE and Incel forums. There was a significant jump in the five weeks after the WHO's declaration on Incels.co. Also of note, the increase in posts on the online forums were in posting frequency by individual users. Yet, there was no change in the amount of posts online for left-wing and Jihadist forums after the declaration. Dr. Davies concluded from this research that the pandemic may have caused an increase in radicalization among RWE and Incels online. However, there were several limitations of the study, including a short follow-up period, the content of the posts was not analyzed in depth, and overall, more evidence is required to show a conclusive causation between the pandemic and the increase in radicalization among RWE and Incel groups. For example, demonstrating the causal reasons as to why there was an increase in posts, and where the increase in posts online occurred.

\section{Question Period}

The shift of Jihadism to RWE has created a real and true threat of radicalization on the West Coast. The pool of potential recruits appears to be much larger in the West Coast regarding RWE than for Jihadism. It is possible that COVID-19 is contributing to an increase in RWE radicalization online, but offline activity is still present as well. Dr. Davies acknowledged that more research is still being conducted to find out whether the primary reason for the increase of activity is due to more time online during the pandemic or whether it is due to other reasons. This is being examined by looking into the use of aggressive language. Additionally, his research indicated a possible rise in Incel posts as they become more present online. One way of combating extremist groups online is to deplatform, which was the case with Parler. Dr. Davies stated that studies have shown a significant impact in decreasing communication between groups when they are de-platformed because the likelihood of them continuing their communication on another platform is low. However, he warned that the solution of de-platforming may not be the best option.

\section{KEY POINTS OF DISCUSSION}

\section{Presentation}

- The prevalence of disinformation and conspiracy theories has possibly increased online during the COVID-19 era. 
- Dr. Davies' study appears to illustrate an increase in online radicalization, but no definitive causal link has been made.

- An increase of RWE and Incel posts on online forums was examined after the WHO's declaration of COVID-19 as a pandemic.

- The study appeared to show no significant changes in left-wing extremism and Jihadism posts online during the pandemic.

\section{Question Period}

- In regard to an increased online pool of recruits, RWE has likely become a larger violent extremist threat on the West Coast than Jihadism.

- Studies have shown de-platforming has impacted communication between groups; however, de-platforming groups should be used with caution.

- It is possible that COVID-19 is affecting the prevalence of activity of RWE.

\section{(c) (i) $\ominus$}

EY NC ND This work is licensed under a Creative Commons Attribution-

\section{NonCommercial-NoDerivatives 4.0 International License.}

(C) (GARTH DAVIES, 2021)

Published by the Journal of Intelligence, Conflict, and Warfare and Simon Fraser University

Available from: https://jicw.org/ 